International Journal of Engineering \& Technology, $7(2.13)(2018) 13-17$
International Journal of Engineering \& Technology
Website: www.sciencepubco.com/index.php/IJET
Research Paper

\title{
Maintenance of Russian secondary school students' health (organizational and administrative aspect)
}

\author{
Natalia V. Tretyakov*1, Vladimir A. Fedorov², Evgeniya V. Ketrish ${ }^{3}$ and Oleg M. Permyakov \\ ${ }^{1}$ Doctor of Education, Professor of Institute of Humanitarian and the socio-Economic education, Russian State Vocational-Pedagogical \\ University, Ekaterinburg, Russia. \\ ${ }^{2}$ Doctor of Education, Professor of Russian State Vocational-Pedagogical University, Ekaterinburg, Russia. \\ ${ }^{3}$ Candidate of Pedagogic Sciences, Associate Professor of Institute of Humanitarian and socio-Economic education, Russian State \\ Vocational-Pedagogical University, Ekaterinburg, Russia. \\ ${ }^{4}$ PhD student, lecturer of Institute of Humanitarian and the socio-Economic education, Russian State Vocational-Pedagogical \\ University, Ekaterinburg, Russia. \\ *Email : tretjakovnat@mail.ru
}

\begin{abstract}
The relevance of the investigated problem is caused by the need to ensure the quality of educational institutions activities aimed at students' health maintenance through the creation of conditions for the organization and management of the activity.

The purpose of the article is to develop organizational and pedagogical conditions of maintenance management process, to preserve students' health. Leading methodological approach to the study of this problem is systematic approach that allows considering educational organizations activities aimed at health maintenance as a certain system, to identify a specific set of its constituent elements and show their relationship. The article presents a structural-functional model of health service and according to management principles 1) covers the main areas of activity (labor division principle); 2) identifies the basis of their structural units (structuring principle); 3 ) the functions of health service activity as a whole, its subsidiaries and certain performers (functional operations accounting principle); 4) provides integrative management performance criteria for health service activities. The information contained in the article may be useful to teachers in terms of the organization of activity on health maintenance in educational institutions by changing organizational and management component of this activity.
\end{abstract}

Keywords: Students' Health Maintenance, Health Services Structural-Functional Model, Health Maintenance Activities Areas, Integrative Management Criteria.

\section{Introduction}

Today, schools are responsible for the students' health and take measures to preserve their health. The main institutional focus of this activity is to create a health service, the purpose of which is to assist supervisory and teaching staff of the institution in the creation of the conditions that will guarantee the students' health protection and maintenance. These structures creation enables the interaction of teachers, psychologists, social workers, medical and educational institutions in joint health activities.

As of today these services gained some practical experience [1]. However, it is not necessary to speak about their infrastructure. It is difficult for these services to intrude into education institutions, their objectives, activities areas and participants are different $[2,3]$.The main reason for this is the number of unresolved issues relating to the fundamental organizational and pedagogical conditions that ensure health services functioning.

In view of the persistent downward trend in the rising generation health, the existing socio-economic conditions, experience and regulations [4], as well as to ensure the quality of health maintenance activities [5], it seems to be appropriate to introduce to educational institutions such the organizational structures as health services. It should be noted that due to the varied and contradictory models available, the lack of conceptual elaboration of the organizational structure it is necessary to develop a universal and acceptable for each educational institution structural-functional model of the service.

The purpose of this research, the results of which are shown in this article is to justify and determine the organizational and pedagogical conditions for ensuring students' health maintenance management process in educational institutions through the creation of structural and functional health service model.

\section{Materials, Methods and Methodological Framework}

\subsection{Research methodology}

ystematic approach is the leading research methodological basis [6] It allowed considering the object of the research - educational institutions activities in the field of students' health maintenance as a certain system belonging to a higher order system; identifying a set of its constituent elements in the system and showing their relationship.

The research methodology is enriched with social systems control theory $[7,8]$. and the main provisions for managing educational institutions and training activities $[9,10,11]$. Using these theories it is possible to determine the basic requirements for health service organizations as a separate structural element in the educational organization. 


\subsection{Research methods}

To solve the research problems, complex research methods were used: 1) theoretical: methodological, psycho-pedagogical and economic literature analysis; study of regulatory documents in the field of education; systems analysis; generalization; modeling; 2) empirical: the study and accumulation of teaching experience; experimental research work.

\subsection{Experimental search database}

Experimental search database of the research are the educational organizations of Ural and Siberian regions of Russia.

\section{Results}

In the construction of the health service, the structural-functional model based on block-target structures, formed according to the matrix type of control, was used. This model allows examining in detail the components and functions of the system, connections of its structures.

The study of the basic notions and provisions of management concept made it possible to determine the basic requirements for the organization of the health service as a separate structural element in the educational institution.

It is established that the concept of "organization" has several meanings: 1) internal interaction orderliness, consistency of more or less differentiated and autonomous parts of the whole, conditioned by its structure; 2) set of processes or actions, leading to the formation and perfection of the relationship between the parts of the whole; 3) consolidation of people implementing a program or purpose and acting on the basis of certain procedures and rules[12]

In the literature, in the general management aspects, the term "organization" is used usually in two senses. First, as a kind of property, consisting in a rational combination and ordering of all elements of a specific object [13]. In this sense, organization can be regarded as a process of interaction between people to achieve a goal. Secondly, organization is interpreted as an object itself, having a certain ordered structure [14]. In this case it is nothing but a certain community (unity) of people who need to combine forces to do something that none of them could achieve alone[14].Thus, organization as a property and process is the content whereas organization as an object and community is nothing else but the form of the content.

In order to solve difficult problems related to maintaining students' health, it is necessary to involve the entire teaching staff into this work and rationalize it. It is clear that in the optimal case this "ordered activity" will become much more effective if it is carried out within the framework of a certain community. We considered this community (health service) as an organization with all its inherent features.

All forms of organization are characterized by the following: 1) at least two of its employees consider themselves to be part of this group; 2) at least one goal is aimed at satisfying the needs or interests of a person or society, which is accepted as the general by the members of this group; 3) team members who deliberately work together to achieve a goal meaningful for everyone; 4) a set of functional provisions and roles; 5) formalization of a significant part of goals and relations; 6) receipt of surplus products in various forms $[15,16]$.

The concept of "management" as a condition for existence and a system-forming feature of organization is closely associated with organization. The study of management issues $[17,18,19]$. allowed allocating in relation to health service planning, organization, control and goal-setting functions, which should be implemented in accordance with the basic principles of education management: the optimal ratio of centralization and decentralization; unity of one-man management and collegiality; rational combination of rights, duties and responsibility.
From the standpoint of system approach, every organization is an open system. The main parts of the system are related to each other in a certain way by formal and informal structures, communication channels and decision-making processes. In accordance with the system approach, the system is not only uniquely determined by the properties of its elements or their groups not being reduced to them, but the elements themselves are determined by the whole being functionally explained within the whole. The theory of systems became the methodical basis for the majority of intraschool researches $[19,20]$. which showed the prospects of considering educational organization as a system, since this approach allows considering the interconnections of the elements more precisely and clearer, revealing the general structure, defining the general structure of its constituent elements. According to this provision, from our perspective health service as a system (organization) is a set of interconnected elements, whereas the way they are connected determines the features of its structure. The level of integrity of health service as a system depends on its targets, completeness of the set of its constituent components, quality of each component and adequacy of the interrelations between them.

Integration is a common feature of all systems being the result, obtained from the interaction of components entering the system, and depending on the level of the system integrity. Accordingly, as the construction of any organization, the creation of a health service (as a relatively independent structural unit in the educational organization) implies following interrelated principles: 1) labor division or specialization; 2) structuring; 3) consideration of function operations (processes).

So, the organization won't work effectively if all its employees will duplicate the work of each other or if one employee takes on all the functions of the organization. Therefore, any social organization is characterized by the division of labor between its members and subsystems that is specialization.

In accordance with the principle of labor division and taking into account the specifics of health service activities, in our opinion, it is necessary to identify five main areas of activity (specializations):

1) medical, sanitary and hygienic assistance, related along with providing proper sanitary conditions of the educational process, to the need for medical maintenance of students (as well as other subjects of the educational process), diagnosing the state of health, and then analyzing and developing appropriate recommendations, adopting preventive measures;

2) forming personal educational process subjects' health saving position by pedagogical means[21] which necessitates the theoretical and methodological development of the rationale, identification and effective use of educational technology, methods and means of formation of students' preparedness for health oriented educational activities;

3) physical education and health maintenance is determined by the special significance of physical education and development of conditioned physical qualities creating the potential of physical health; this direction provides appropriate theoretical and methodological development for the substantiation, definition and effective use of physical education and health technologies, methods and tools in the educational process;

4) psychological and educational support associated with the need to support students through the implementation of developmental and remedial, systematically and individually oriented programs;

5) monitoring the level of physical development and health status of students, which is determined by the need to collect, promptly process, systematize and store information about the health status of students in order to identify risk factors and timely take corrective and preventive measures that provide substantial, organizational and managerial monitoring development.

Specialized labor in comparison with non-specialized one has a number of advantages: it allows understanding in detail the essence of the matter, faster and more exactly defining the 
problems that contributes to the search for ways to perfect the performance of the executor; simplify communication system: the highly specialized worker does not need frequent contacts with colleagues and management team; specialization allows for raising the quality of professional tasks, makes labor more economic. At the same time, the specialization of labor leads to the complication of coordination problem and presents the problems associated with the management of the organization as a whole. Departmentalization, tasks grouping and structural units formation are intended to solve them, as well as to increase control level.

When forming structural units, it is important to identify the tasks for which implementation it is required to carry out specialized task or jointly use resources, and also to exchange them when performing similar tasks.

In view of the trends in students' health maintenance the health service, as a relatively independent of the structural organization, should be divided into structural units (structuring principle) vested with certain powers and responsibilities: 1) health and hygiene; 2) valeological and pedagogical; 3) athletic and recreational; 4) psycho-pedagogical; 5) monitoring.

The structure of the organization's management system should reflect subordination principles as well as direct and indirect cooperation links, hence, individual subjects' functions, responsibilities and rights importance increase.

According to M. M. Kalidium (2000) "organizational structure" is a set of individual and collective actors, who are characterized by the authority and responsibility for the completion of management functions shared between them as well as regularly reproducible links and relationships. The organizational structure is usually depicted in the form of a scheme, called organigram, which shows subjects and links between them: subordination (coordination relations). This is a kind of control system skeleton.

There are several types of organizational structures of control systems: linear, functional, linear-functional, project and matrix [22,23].

When building the organizational structure of a health service, it should be decided whether the responsibility for future projects implementation will be shared between the sub-sections presented and whether they will be coordinated vertically, or task groups that will be responsible for the implementation of the whole projects will be gathered. In the first case, we are talking about the distribution of new powers and responsibilities within the framework of a linear-functional structure, and in the second, the creation of design or matrix structure.

The first option is more customary, but it has its drawbacks inherent in linear-functional structures (lack of close linkage between structural subdivisions; lack of clearly shared responsibilities, since those who prepares a decision, as a rule, does not participate in its implementation; an excessively developed vertical interaction system, namely, submission according to management hierarchy, that is a tendency to overcentralization). The second option requires a good horizontal communication in a health service team and sufficiently high level of their development. In this case, the organizational structure of the service should be built in mixed form, e.g., linear-functional structure with matrix elements. Since linear-functional structure solves certain tasks more efficiently and imposes less strict requirements on the versatility of managers and executives training that is undoubted advantage, whereas matrix structure allows significantly raising management flexibility.

It should be noted that if a structural organization faces system management transformations, there should be individual and collective actors who develop and implement these innovations. Since it is followed by the increasing role of coordination of interaction between all subjects of the structure, the subjects of top levels - executives - turn to be the most loaded. In this case, the transfer of decision-making powers to the entities at the lower levels of the organizational structure is an important step.
Consequently, the head of health service must be a person vested with corresponding rights and responsibilities. In addition, each unit of it must be headed by the most responsible, competent and active employees - leadership of unit or responsible for the core processes of the educational organization in the field of students' health maintenance[24].At the present moment, in our opinion, one of the main reasons that, despite the existing policy documents on conservation and health promotion in educational institutions, health status of students does not improve, is the lack of staff "unit", responsible for implementing measures that provide for students' health maintenance.

Organizational structure is just a static model, which reflects, according to the figurative expression of B. Z. Milner, the organization "anatomy", whereas the actions of the units and the actors themselves are the "physiology" which stipulates for directed efforts to address the problems it faces. This raises the need to implement the following classical principle of organization building - the principle of the functional operations accounting, that is what health service units and people involved (their functions) should be engaged with [25].

In accordance with the principle of functional operations (processes) it is advisable to allocate three main functions of activity as a health service as a whole, and its subsidiaries:

1) diagnostic and prognostic - conducting system of students' health diagnostic tests in the framework of the basic processes / activity areas of educational organizations, defining corrective and preventive actions that contribute to the achievement of expected results;

2) information and advisory - generalization and systematization of factual material within a particular process / activity aimed at students' health maintenance at theoretical and empirical levels, informing the public about the results of ongoing operations, the provision of advice on the maintenance and promotion of students' health;

3) research coordination - coordination of efforts of the experts of various levels and profiles to develop constructive strategies and scientific and methodological support of measures aimed at students' health maintenance.

In our opinion, integrated management criteria of health service activities efficiency in accordance with the provisions of the education management theory, should be the following indicators: 1) consistency and regularity in the activities organization; 2) activity and productivity; 3 ) operability and accuracy in the functioning.

Consistency and regularity in the organization of health services activities are characterized by clearly defined goals, objectives; precise distribution of functional responsibilities; well-designed evaluation criteria of units performance; systematic efficiency analysis of the solutions made and executed; ordered ICU system informing about the actions and their effectiveness.

The activity and productivity of the activities are determined by the number of initiatives to improve management team performance and new types of activities on the students' health maintenance coming from the structural units; and many new implemented solutions; supervised areas of activity, targeted and innovative projects and others.

Work efficiency and accuracy are determined by timely plan execution (the number of actions performed optimally and efficiently in correlation with the bad managed ones) and the consistency in carrying out the actions.

The content of the described areas is integrated, in our view, with all the aspects of the educational organization in the field of preservation and promotion of students' health with the possibility of interdepartmental social partnership.

Thus, the construction of health services allows for efficient organization and structuring of educational institutions activities to maintain and promote the students' health.

\section{Discussions}


The analysis of pedagogical literature allows ascertaining the absence of specific studies on the issue of ensuring the quality of educational institutions activities aimed at the preservation of students' health through the creation of conditions for the organization and management of the activities.

Thus, a number of studies reviewed these structures organization in urban conditions [26], regional educational complexes [27,28]., but their organization directly in educational institutions doesn't compel enough attention. The organizational activities, which consists in the distribution of the actions undertaken to achieve the service goals, between individual professionals followed by revealing the connections between them, wasn't indicated.

To solve the problem, we used methodological basis for management issues study. As early as in the beginning of $20^{\text {th }}$ century researchers defined three types of management: social, biological and technical. Managing of educational systems refers to the social mind: impact on society for the purpose of ordering and maintaining quality specifics.

Studying the works of the Russian scientists, Yu A. $[29,30]$ revealed that education system management is an integrated process, the core of which is the development of scientific fundamentals for education process management.

The reference to pedagogical dictionaries revealed that management is treated as a function of organizational systems of different nature (biological, social, technical) to ensure the preservation of their particular structure, maintenance of the activity, programs and goals implementation. This provision became the basis for the creation of health services.

When creating a health service structure it is necessary to determine to what type of organizational structure refers this management systems. The structures can be linear, functional, linear-functional, project and matrix.Traditional structures of intraschool management refer to the structures of linear-functional type. They are characterized by two or more hierarchical management levels, at each of which a group of employees is under a manager, and the relationship between managers and subordinates is based on the principle of one-man management. The structures of this type, along with the hierarchy of line management, include functional units (teachers' council, methodological and other associations vested with functional authority), specialized in the implementation of certain type of management actions and deciding on a limited range of specific issues.

Through specialization linear-functional structures allow solving certain problems more qualitatively making fewer requirements on the versatility of managers and executives training that is their undoubted merit. However, in instable external conditions or when it is necessary to solve a lot of unusual problems that requires joint work of different units, these structures turn to be inefficient, because they lack flexibility. Besides functional differentiation leads to the loss of the general objectives of the entire system, which are out of its business units view. Each unit is occupied only with its part of tasks, and only the head of the organization is the bearer of common goals.

In this situation, the structures of project and matrix types are more flexible. Project structure is a temporary structure created to solve some major challenges. To this end, a group of employees as well as experts "from somewhere around" that can cope with the task become one team. The simultaneous implementation of many projects leads to the appearance of matrix-type structures, where one and the same employee is included in several project teams and is subject to a number of project managers. But these mangers do not have administrative privileges - they remain assigned to the heads of departments. Project managers define only "what" and "when" is to be done. "Who" and "how" it will do are defined by the heads of departments. Matrix structures allow significantly improving management flexibility, but at the same time, high demands are imposed on the managers' competencies and to the maturity of the staff level.
In management theory linear functional structure refers to mechanical class whereas design and matrix type structures - to organic (or adaptive) class. Structures of mechanical type are characterized by a rigid division of powers and responsibilities, deep sharing of the administrative functions of units and positions . Each expert solves his own problem as something separate from the real challenges faced by the organization in general.

Addressing new challenges organic type structures are able to flexibly change the composition of their bodies and the links between them. These structures provide for regular emergence of temporary structural units oriented at the solution of some problems and projects implementation. Experience and qualification prevail over organizational status.

Knowing this we managed to select linear-functional structure with matrix elements as the organizational structure of health service.

The study of management issues led to the understanding that the very management functions implementation is relatively isolated area of management activities. In particular, constructing his "management building", A. Fayolle divided administrative function into primary elements, calling them basic management functions: planning is a system of practical measures interconnected and united by common goals; organization is a well conceived apparatus, the structure of the institution and its function; control is checking, the process of obtaining the information about a progress and results of operations speaking of the control functions of educational institutions adds the stimulation and analysis to the above functions; M. M. Potashnyk (2000) considers such features as primary analysis, forecasting, programming, organization, regulation, control, analysis, correction and stimulation; T. I. Shamova (1992) highlights information and analysis, innovational-target, planningprognostic, organizational-examinational and regulatorycorrective functions. Generalization of this knowledge allowed defining integrative health service functions: diagnostic and prognostic, informative-advisory and scientific-coordinative.

\section{Conclusion}

Quality assurance of students' health maintenance in educational institutions requires systematic specific work, which, of course, must be organized in a certain way. The very organization is always required when it is necessary to ensure agreement in the work of people and rational ordering of their activities aimed at achieving a goal. Health service serves as a model of this organization.

Designing the health service, as well as designing any structure in the organization, we adhered to a number of interrelated principles: labor division or specialization, structuring, functional operations accounting.

In accordance with the principle of labor division or specialization, taking into account the specifics of the students' health maintenance measures, five main areas of health service activity (specializations) were identified: 1) medical and hygiene support; 2) educational subjects' personal health saving position formation by pedagogical means; 3) sport and health maintenance; 4) psychological and educational support; 5) monitoring the level of physical development and students' health. In accordance with the areas of health service as a relatively independent structural organization, the structural units (structuring principle), to which certain powers and responsibilities are assigned, were highlighted: 1) medical and sanitary; 2) valeological and pedagogical; 3) sport and recreational; 4) psychological and educational; 5) monitoring.

The areas involve all the aspects of the educational organization in the field of maintenance and promotion of students' health with the possibility of interdepartmental social partnership between its specialists.

Organizational structure formed by units of health services is based in the form of mixing linear-functional structure (it allows 
for more qualitative solutions to the problem and makes fewer requirements on the versatility of managers and executives training that is its undoubted advantage) with the elements of the matrix one (allows for considerable flexibility increase).

The units are headed by their managers; all the service activities are coordinated by the head of health service, vested with corresponding powers.

In accordance with the principle of functional operations three main functions of activity both of health service as a whole and its subsidiaries and certain executors were defined: 1) diagnostic and prognostic; 2) informative and advisory; 3) scientific and coordinative.

Integrated management criteria of the service activities efficiency, in accordance with the provisions of the education management theory are the following indicators: 1) consistency and regularity in the organization of health service activities; 2) activity and productivity; 3) operability and accuracy in the fuctioning.

The proposed health service structure allows delimiting the scope of competence of specialists in various fields involved in health activities, without the assumption of their efforts fragmentation to ensure the preservation of a single strategic vector aimed at achieving the goals set.

The theoretical and methodological aspects of research were practically tested on the basis of educational institutions located in Ural and Siberian regions of Russia.

\section{Recommendations}

The proposed conceptual provisions for creating organizational and pedagogical conditions for management process of students' health preservation in an educational institution through the creation of structural and functional health service model can be used in specific educational organizations:

1) to evaluate the level of health activities for students' health maintenance and their subsequent designing in educational organizations;

2) to evaluate the effectiveness of educational organizations in students' health preservation;

4) to determine the direction of further researches of the processes of assuring qualitative functioning of educational institutions quality in the field of the students' health preservation. The results of the research will be useful to scientists who study the issues of qualitative health maintenance in educational institutions, to teachers working in educational institutions of different types, students of pedagogical universities and other interested parties.

\section{References}

[1] Golikov, N. A. (2006). Pedagogy of sanation in terms of multifunctional educational institution. Tyumen: Tyumen State University, $232 \mathrm{p}$.

[2] Kirillova, M. Yu. (2000). Valeological support of the educational process as a means of formation of younger students' readiness to study in comprehensive school. PhD Thesis. St. Petersburg: St. Petersburg State University of pedagogical skills, p. 189.

[3] Fedorov, V. A . \& Tretyakova , N. V. (2015). Quality management of educational institutions in protecting students' health: conceptual and structural-functional innovations. Bulletin of National Scientific University Mining , 6 (150), 134-143. http://nvngu.in.ua/index.php/ru/

[4] Tretyakova, N. V. (2011). Regulatory and legal basis for children and adolescents' health maintenance in school. Proceedings of $P$. F. Lesgaft University, 1 (71), 124-127.

[5] Tretyakova N.V., Fedorov V.A. Quality of Health Care Activity in Educational Institutions: Conceptual Aspect. The Education and science journal. 2013;4:112-132. (In Russ.) DOI:10.17853/1994-5639-2013-4-112-132

[6] Babansky, Yu. K. (2005). Optimization of educational process. Methodical fundamentals. Moscow: Pedagogy, $193 \mathrm{p}$.
[7] Meskon , M . H., Albert , M . \& Hedouri , F. (1997). Fundamentals of Management. Moscow: Delo, 488 p.

[8] Fayolle, A. Emersonl, G. \& Taylor, F. (1992). Management as a science and art. Moscow: Respublika, $167 \mathrm{p}$.

[9] Lazarev, V. S. (2002). System development of the school. Moscow: Russian Pedagogical Society, 304 p.

[10] Tretyakova, N. V. \& Fedorov, V. A. (2014). Quality control methods to assess the health-maintenance activity of the educational institution. University Management, 1, 32-44

[11] Shamova, T. I. (1992). School management. Moscow: ASTPress, $218 \mathrm{p}$.

[12] Frolov, I. G. (2001). Philosophical Dictionary. Moscow: Respublika, $720 \mathrm{p}$

[13] Gridina, L. W. (2011). Elements of the quality management of the university educational services and process approach. Quality management in high school, 1, 64-70.

[14] Milner, B. Z. (1981). Methods of analysis and organizational structures of management: experience of system research. Moscow: Nauka, 228 p.

[15] Nemova, N. V. (2001). Organization of school functioning and development. Moscow: Academy of continuing training and professional retraining of academic workers, $80 \mathrm{p}$.

[16] Nemova N.V. (2012). School Transition to the State-Social Management System Based on the Project Approach Application. The Education and science journal. 6 :43-65. (In Russ.) DOI:10.17853/1994-5639-2012-6-43-65

[17] Blauberg, I. V. \& Yudin, E. G. (1973). Formation and essence of system approach. Moscow: Nauka, 210 p.

[18] Fulmer, R. M. (2005). Encyclopedia of modern management: in 5 volumes. Moscow: Finance and Statistics, Vol. 2: The organization as a management function, $142 \mathrm{p}$.

[19] Konarzhevsky, Yu A. (2000). Management and intraschool administration. Moscow: Pedagogical Search, 224.

[20] Tretyakov, P. I. (1998). School management based on findings: pedagogic management practice. Moscow: Novaya Shkola, 288 p.

[21] Tretyakova, N. V., Fedorov, V. A., Abramov, D. V. \& Kalimulin, D. M. (2016). Educational Institution Health Service Management: Key Aspects of Communication and Interaction Within the Team. IEJME-Mathematics Education, 11(8), 28412857. http://www.iejme.com/makale/902

[22] Nikitin, A. S. \& Serebrennikov, S. S. (2013). Management theory. St. Petersburg: Piter, 464 p.

[23] Korotaeva, L. A. (1997). Valeological service system organization in the school as a condition for formation of physically and mentally healthy person. PhD Thesis. Kasan: Kazan State Pedagogical Institute, 205 p.

[24] Tretyakova, N. V. \& Fedorov, V. A. (2015). Ensuring effective interaction between heads of departments of health services in educational organizations. Quality. Innovation. Education, 4 (119), 27-37.

[25] Tretyakova, N.V., Fedorov, V.A., Dorozhkin, E.M., Komarova, M.K. \& Sukhanova, E.I. (2016). Formation of Students' Readiness for Activities Oriented to Health Saving. International Journal of Environmental and Science Education, 11(15), 82818292. http://www.ijese.net/makale/1080

[26] Kazin, E. M., Blinov, N. G. \& Litvinov, N. A. (2000). The fundamentals of individual health. Moscow: Vlados $190 \mathrm{p}$.

[27] Kazin, E. M. Panina, T. S. \& Kuraev, G. A. (1993). Centers of scientific bases of health and development. Kemerovo: Regional Institute of continuing education of teachers, $128 \mathrm{p}$.

[28] Khodayari Bavil, A., Razavi, S.E., On the thermo-flow behavior in a rectangular channel with skewed circular ribs, Mechanics \& Industry, 182 (2017) 225, https://doi.org/10.1051/meca/2016057

[29] Kim, S. V. (2001). Valeological support of secondary education. PhD Thesis. St. Petersburg: St. Petersburg State University of pedagogical skills, $126 \mathrm{p}$.

[30] Potashnik, M. M. (2000). Education quality management. Moscow: Russian Pedagogical Community, 448 p. 